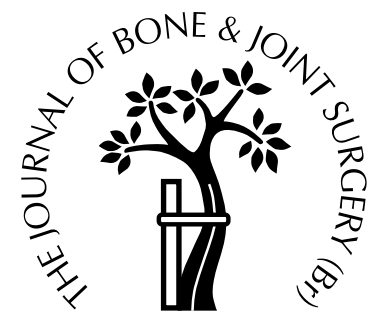

\title{
Treatment of fractures of the distal radius with a remodellable bone cement
}

\author{
A PROSPECTIVE, RANDOMISED STUDY USING NORIAN SRS \\ J. Sanchez-Sotelo, L. Munuera, R. Madero \\ From the Hospital 'La Paz', Madrid, Spain
}

W e performed a prospective, randomised study on 110 patients more than 50 years old with fractures of the distal radius to compare the outcome of conservative treatment with that using remodellable bone cement (Norian skeletal repair system, SRS) and immobilisation in a cast for two weeks.

Patients treated with SRS had less pain and earlier restoration of movement and grip strength. The results at one year were satisfactory in $81.54 \%$ of the SRS patients and $55.55 \%$ of the control group. The rates of malunion were $18.2 \%$ and $41.8 \%$, respectively. There was a significant relationship between the functional and radiological results. Soft-tissue extrusion was present initially in $69.1 \%$ of the SRS patients; most deposits disappeared progressively, but persisted in $32.73 \%$ at one year.

We conclude that the injection of a remodellable bone cement into the trabecular defect of fractures of the distal radius provides a better clinical and radiological result than conventional treatment.

J Bone Joint Surg [Br] 2000;82-B:856-63.

Received 29 June 1999; Accepted after revision 7 February 2000

Fractures of the distal radius in elderly patients are often unstable. The metaphyseal defect which persists after reduction can lead to malunion ${ }^{1,2}$ and decreased function. ${ }^{3,4}$ Most commonly, this fracture is stabilised with a cast or external fixation or Kirschner wires to hold the reduction until the trabecular defect has filled with new bone. ${ }^{2}$ The reported results and rates of complication with these methods, however, are not entirely satisfactory. ${ }^{5,6}$ An alternative approach is to fill the defect primarily with a material which provides structural support. Both bone graft and

J. Sanchez-Sotelo, MD, Consultant Orthopaedic Surgeon

L. Munuera, PhD, Professor of Orthopaedic Surgery

R. Madero, MS, Statistician

Departments of Orthopaedic Surgery and Biostatistics, Hospital 'La Paz', Paseo de la Castellana 261, 28046 Madrid, Spain.

Correspondence should be sent to Dr J. Sanchez-Sotelo at the Department of Orthopaedic Surgery, Mayo Clinic, 200 First Street SW, Rochester, Minnesota 55905, USA.

(C)2000 British Editorial Society of Bone and Joint Surgery 0301-620X/00/610317\$2.00 polymethylmethacrylate (PMMA) have been used for primary stabilisation of fractures of the distal radius with good results, ${ }^{7-10}$ but morbidity at the donor site of the graft ${ }^{11,12}$ and the lack of osseous integration of PMMA ${ }^{13}$ have reduced interest in these methods of treatment. Osteoconductive synthetic materials have become available and may provide some of the mechanical properties of bone. The Norian skeletal repair system (SRS) (Norian Corporation, Cupertino, California) belongs to this group of biomaterials. $^{14}$

The constituents of Norian SRS can be prepared as an injectable product which transforms under physiological conditions into a carbonated apatite similar to the mineral phase of bone. ${ }^{14}$ An in vivo study has shown that Norian SRS is biocompatible, does not interfere with healing of the fracture and is remodelled by the same osteoclastic-osteoblastic process as living bone. ${ }^{15}$ In a cadaver study, Norian SRS provided more stability than Kirschner wires for intraarticular fractures of the distal radius. ${ }^{16}$ Two short clinical series have shown that this product can be safely used for these fractures ${ }^{17,18}$ and one study has compared Norian SRS with external fixation. ${ }^{19}$ A comparison of SRS with conservative treatment has not previously been reported. We have compared the outcome using Norian SRS with that after simple closed reduction and immobilisation in a cast for six weeks, in matched groups of patients over 50 years of age.

\section{Materials and Methods}

Between January and May 1998 all patients who presented with a fracture of the distal radius at our institution were included in the study provided that they fulfilled the following criteria: 1) age 50 to 85 years; 2) $\mathrm{AO}$ type $\mathrm{A} 3$ or $\mathrm{C} 2$; 3) occurrence of the fracture within 24 hours of presentation; 4) absence of associated injuries in the upper limb or contralateral wrist; and 5) absence of previous injuries to the fractured wrist. They all gave their informed consent. There were 110 patients and they were randomly selected for either closed reduction, stabilisation by Norian SRS and a cast for two weeks (SRS group, 55 patients) or closed reduction and a cast for six weeks (control group, 55 patients). In all patients the injury had been caused by a fall from a standing height; there were no high-energy injuries. 
Table I. Continuous variables for patients in both groups (mean \pm SD)

\begin{tabular}{lcc}
\hline & Norian SRS & Control \\
\hline Age (years) & $65.18 \pm 6.10$ & $66.87 \pm 6.56$ \\
Original volar angle (degrees) & $-20.4 \pm 7.26$ & $-22.07 \pm 5.71$ \\
Original radial angle (degrees) & $10.78 \pm 3.88$ & $10.24 \pm 3.1$ \\
Original radial length (mm) & $6.22 \pm 2.04$ & $5.76 \pm 1.72$ \\
Original radial width $(\mathrm{mm})$ & $2.04 \pm 0.86$ & $2.05 \pm 0.62$ \\
Original ulnar variance $(\mathrm{mm})$ & $1.51 \pm 0.86$ & $1.82 \pm 0.86$ \\
\hline
\end{tabular}

Table II. Categorical variables or patients in both groups, by number and percentage

\begin{tabular}{lrr}
\hline & Norian SRS & Control \\
\hline Gender & $7(13.73)$ & \\
$\quad$ Male & $48(87.27)$ & $69(10.91)$ \\
$\quad$ Female & & \\
Side & $20(36.36)$ & $18(32.73)$ \\
$\quad$ Right & $35(63.64)$ & $37(67.27)$ \\
$\quad$ Left & & \\
Dominance & $25(45.45)$ & $24(43.64)$ \\
$\quad$ Dominant & $30(54.55)$ & $31(56.36)$ \\
$\quad$ Non-dominant & & \\
AO type & $38(69.09)$ & $35(63.64)$ \\
A3 & $17(30.91)$ & $20(36.36)$ \\
C2 & & \\
Intra-articular gap (mm) & & \\
in AO type C2 & $7(41.18)$ & $9(45)$ \\
1 & $8(47.06)$ & $2(0.1)$ \\
2 & $2(11.76)$ & \\
3 & & \\
\hline
\end{tabular}

Tables I and II summarise the initial features for both groups. There were no significant differences between them in terms of age, gender distribution, side or type of the fracture, initial displacement or instability of the fracture according to the score of LaFontaine, Hardy and Delince. ${ }^{20}$ Only nine patients in the SRS and six in the control group were manual workers. All patients in both groups were treated by the first author (JSS).

Treatment protocol in the SRS group. The fracture was reduced in traction using a fingertrap system monitored by fluoroscopy. After closed reduction, an elevator was introduced into the site of the fracture through a dorsal, longitudinal, incision of $1 \mathrm{~cm}$ to remove haematoma, debris and loose fragments both towards the subchondral area and proximally to provide a regular cavity which was flushed with saline. A $5 \mathrm{~cm}^{3}$ Norian SRS pack was then mixed and injected, filling the defect. Traction was maintained, fixed to the surgical table, to ensure that no movement occurred while the cement set. The time of injection was always less than two minutes. The limb was then kept immobile for a further ten minutes to avoid disruption of the cement. The skin was when closed and a below-elbow cast applied in slight volar flexion and ulnar deviation. Active assisted movement of the digits, elbow and shoulder was encouraged. The cast was removed at two weeks, after which the patient was allowed free use of the affected wrist for daily activities, avoiding heavy loads until 12 weeks after fracture.
Treatment protocol in control group. The fracture was reduced using traction and closed manipulation. A belowelbow cast was applied in slight volar flexion and ulnar deviation. Active assisted movement was encouraged for the digits, elbow and shoulder. Some degree of redisplacement occurred in 38 patients, requiring manipulation and a change of cast. The cast was finally removed at six weeks. Free use of the affected wrist for daily activities was then allowed, avoiding heavy loads until 12 weeks after fracture.

Assessment of outcome. All patients were examined at six weeks and at three, six and 12 months after injury. The complications were recorded and a research physiotherapist made an analysis of the function of the wrist and hand, including radiocarpal and radio-ulnar pain measured from 0 to 100 on a visual analogue scale (VAS) in terms of intensity. The range of movement for each wrist was measured using a goniometer and grip strength measured for each hand using a JAMAR dynamometer (Therapeutic Equipment Corporation, Clinton, New Jersey). The range of movement and grip strength were translated into percentages of function recovered by the fractured wrist compared with the uninjured side. The final functional results were graded using the clinical scoring system of Green and O'Brien as modified by Bradway, Amadio and Cooney. ${ }^{21}$ For this scoring system, VAS ratings for pain were divided into three groups: 1 to 29,30 to 69 and 70 to 100 which were classified respectively as mild, moderate or severe.

Anteroposterior and lateral radiographs of the fractured wrist were taken immediately after treatment and at one, two and six weeks and at three, six and 12 months after the fracture. Anteroposterior and lateral radiographs of the contralateral wrist were taken at the initial visit for comparison. The following parameters were measured on each set of radiographs: volar angle, radial angle, radial length, radial width, ulnar variance and intra-articular gap. ${ }^{2}$ The presence and evolution of extraosseous cement were assessed radiologically in the SRS cases. Malunion was defined as a dorsal angle greater than $10^{\circ}$, radial shortening greater than $5 \mathrm{~mm}$ compared with the contralateral wrist, and/or incongruity of the joint surface greater than $2 \mathrm{~mm}$ at 12 months. $^{2,4}$

Statistical analysis. Analyses were performed using SPSS 8.0 for Windows software (SPSS Inc, Chicago, Illinois). The similarities or differences between the two groups in terms of initial features, functional results, radiological appearances and complications were analysed using chisquared tests for categorical variables, the Student $t$-test for continuous variables and, where comparisons included the LaFontaine score, the Mann-Whitney U test. The same tests were used to assess the relation between functional and radiological results. Relative ranges of movement, grip strengths and radiological parameters were analysed using the Pearson correlation coefficients or Spearman rank correlation coefficients, depending on the scale of measurement. The relationship between radiological parameters and 
Table III. Mean ( \pm SD) ranges of movement and mass grip strength, expressed as percentages of the normal side, at six weeks, three months, six months and one year

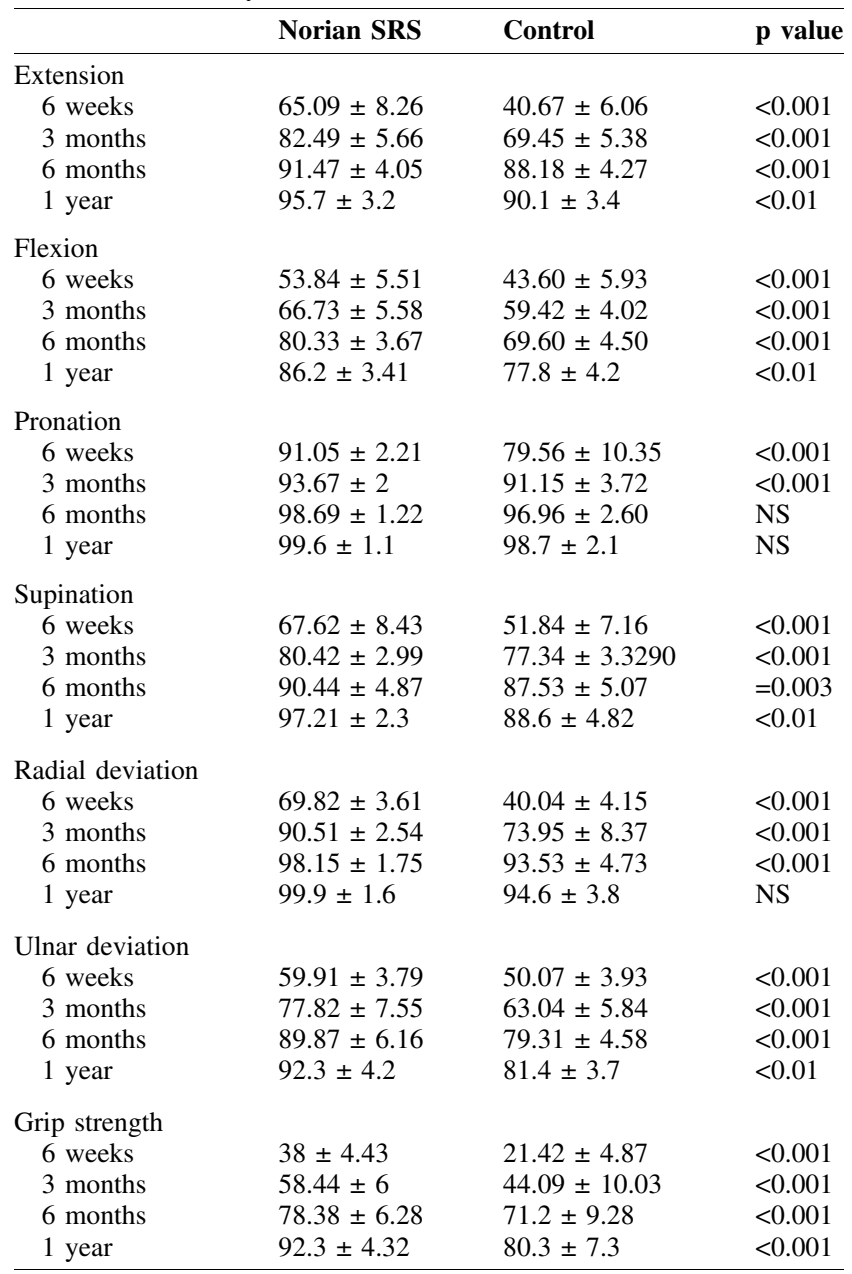

Table IV. Radiocarpal pain according to the VAS scale in both groups, by number and percentage

\begin{tabular}{lcc}
\hline & Norian SRS & Control \\
\hline 3 months & & \\
None & $41(74.5)$ & $29(52.7)$ \\
Mild & $5(9.1)$ & $10(8.2)$ \\
Moderate & $6(10.9)$ & $9(16.4)$ \\
Severe & $3(5.5)$ & $7(12.7)$ \\
6 months & & \\
None & $47(85.4)$ & $34(61.8)$ \\
Mild & $3(5.5)$ & $13(23.6)$ \\
Moderate & $4(7.3)$ & $5(9.1)$ \\
Severe & $1(1.8)$ & $3(5.5)$ \\
12 months & & \\
None & $48(87.3)$ & $40(72.7)$ \\
Mild & $6(10.9)$ & $4(7.3)$ \\
Moderate & - & $9(16.4)$ \\
$\quad$ Severe & $1(1.8)$ & $2(3.6)$ \\
\hline
\end{tabular}

Table V. Radio-ulnar pain according to the VAS scale in both groups by number and percentage

\begin{tabular}{lrr}
\hline & Norian SRS & Control \\
\hline 3 months & & \\
None & $45(81.8)$ & $30(54.5)$ \\
Mild & $4(7.3)$ & $8(14.5)$ \\
Moderate & $4(7.3)$ & $11(20.0)$ \\
Severe & $2(3.6)$ & $6(10.9)$ \\
6 months & & \\
None & $48(87.3)$ & $32(58.2)$ \\
Mild & $4(7.3)$ & $12(21.8)$ \\
Moderate & $2(3.6)$ & $7(12.7)$ \\
Severe & $1(1.8)$ & $4(7.3)$ \\
12 months & & \\
None & $49(89.1)$ & $38(69.1)$ \\
Mild & $3(5.5)$ & $8(14.5)$ \\
Moderate & $2(3.6)$ & $6(10.9)$ \\
Severe & $1(1.8)$ & $3(5.5)$ \\
\hline
\end{tabular}

the functional result was assessed through an analysis of variance using Bonferroni's multiple comparisons. Stepwise logistic multiple regression analysis was used finally to adjust the association of both functional and radiological results with the method of treatment. All tests of significance were two-tailed. Statistical significance was established at $\mathrm{p}<0.05$.

\section{Results}

Functional. Patients in the SRS group recovered movement in all planes earlier than the control group (Table III). The differences in mean movement were statistically significant at six weeks and at three and six months, but thereafter decreased progressively. At six weeks, the SRS group had a greater mean extension of $24.42 \%$, mean flexion of $10.24 \%$, mean pronation of $11.49 \%$, mean supination of $15.78 \%$, mean radial deviation of $29.78 \%$ and mean ulnar deviation of $9.84 \%$. At three months, the increased differences in the mean movement had fallen to extension $13.04 \%$, flexion $7.31 \%$, radial deviation $16.56 \%$ and ulnar deviation $14.78 \%$; the differences in mean prona- tion and supination were only $2.52 \%$ and $3.05 \%$. After six months, the positive differences were around $10 \%$ only for mean flexion and ulnar deviation and less than $5 \%$ in the other planes.

The SRS group also recovered grip strength earlier, although again differences decreased over time (Table III). At six weeks, the SRS group had a greater mean grip strength of $16.58 \%$. The respective differences in grip strength at three, six and 12 months were $14.35 \%, 7.18 \%$ and $12 \%$.

The incidences of radiocarpal and radio-ulnar pain were similar in both groups at six weeks but greater in the control group at three, six and 12 months. At six weeks, $36.36 \%$ of SRS patients and $41.82 \%$ of the control group had radiocarpal pain. The incidence at three, six and 12 months in the SRS and control groups were, respectively, $25.45 \% \quad v \quad 47.27 \% \quad(\mathrm{p}=0.018), \quad 14.55 \% \quad v \quad 38.18 \%$ $(\mathrm{p}=0.005)$ and $13.73 \% \vee 27.27 \%(\mathrm{p}<0.01)$. At six weeks radio-ulnar pain was present in $69.09 \%$ of patients in each group. At three, six and 12 months the respective incidences in the SRS and control groups were $18.18 \% v$ $45.45 \%(\mathrm{p}=0.009), 12.82 \% \vee 41.82 \%(\mathrm{p}=0.007)$ and 

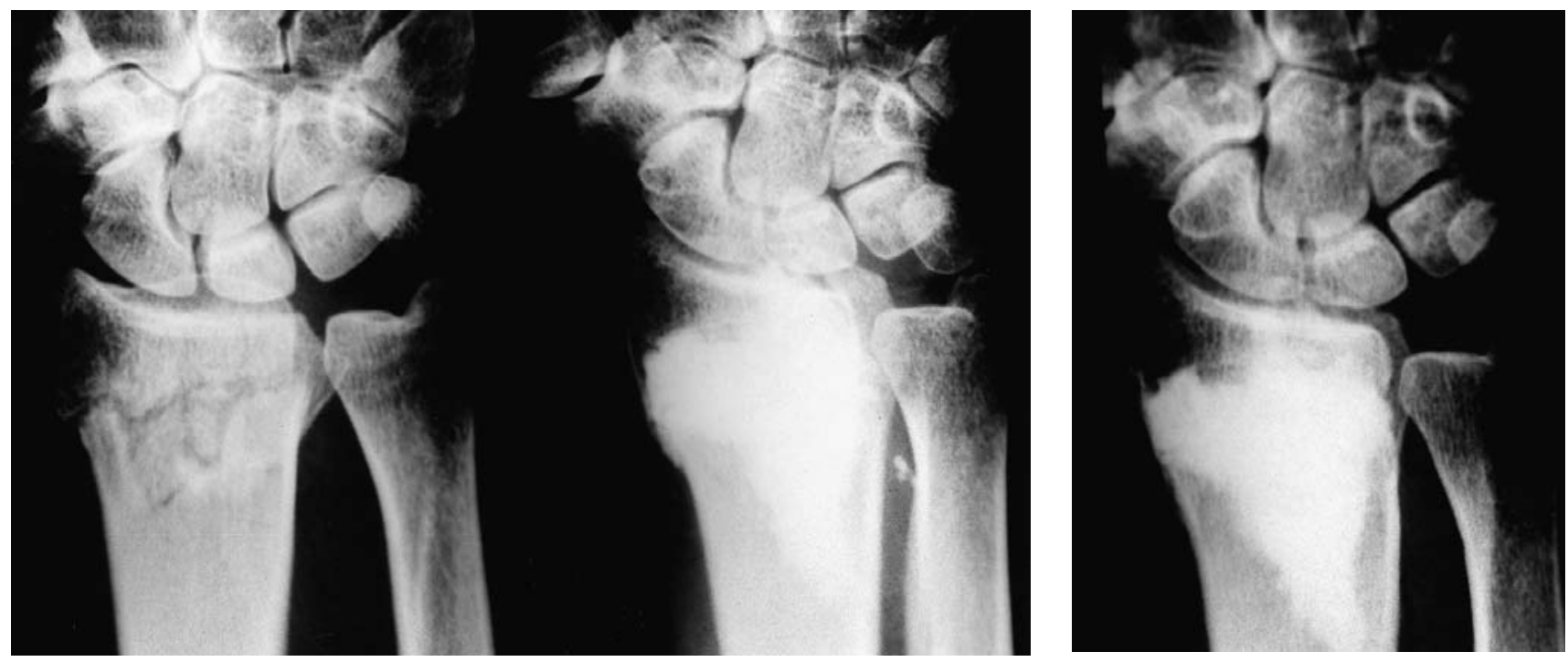

Fig. 1a

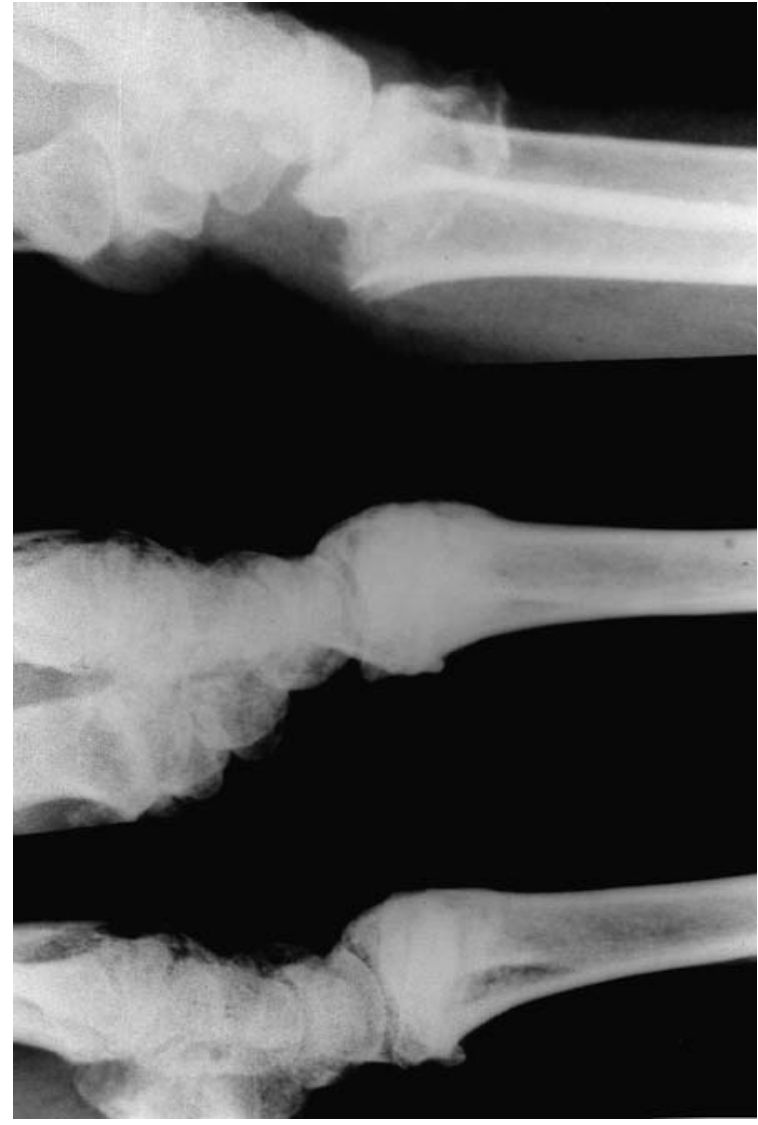

Fig. 1b

$10.9 \%$ v 30.9\% ( $\mathrm{p}<0.01)$ (Tables IV and V).

According to the modified clinical scoring system of Green and O'Brien, the results in the SRS group at one year were graded as excellent in $30(54.55 \%)$, good in 15 (27.27\%), fair in seven (12.72\%) and poor in three (5.45\%). In the control group, they were excellent in 17 (30.91\%), good in 13 (23.64\%), fair in $13(13.64 \%)$ and poor in 12 $(21.82 \%)$. There was a significant difference between the
Radiographs of an extra-articular unstable fracture treated by Norian SRS and immobilisation in a cast for two weeks showing a) AP views before treatment, at six weeks and at one year and b) lateral views before treatment, at six months and at one year (top to bottom). Note the stability provided by SRS in this case with no changes in radiological position from six weeks to one year.

rates of satisfactory (good and excellent) results obtained in the SRS (81.54\%) and control (55.55\%) groups $(\mathrm{p}=0.012)$.

Radiological. The quality of the initial reduction obtained in both groups was similar. The differences between the SRS and control groups on postreduction radiographs were as follows: mean volar angle, $10.93^{\circ} v 11.11^{\circ}$; radial angle, $22.13^{\circ} \vee 22.29^{\circ}$; radial length, $11.11 \vee 10.75 \mathrm{~mm}$; radial width, $0.16 v 0.22 \mathrm{~mm}$; ulnar variance, $-1.95 v-1.18 \mathrm{~mm}$; and intra-articular gap, $0.29 v 0.1 \mathrm{~mm}$. None reached statistical significance.

Both groups showed some progressive settling of the fracture, which was greater in the control group (Fig. 1). Figure 2 shows the radiological evolution in both groups. The mean volar angle at one year was $3.59^{\circ}$ in the SRS and $-3.19^{\circ}$ in the control groups, with losses during follow-up of $7.34^{\circ}$ and $14.3^{\circ}$, respectively. The final mean radial length, expressed as its excess over the length of the ulna, was $7.31 \mathrm{~mm}$ in the SRS and $4.65 \mathrm{~mm}$ in the control groups; they had lost $3.8 \mathrm{~mm}$ and $6.1 \mathrm{~mm}$, respectively. In the SRS group, the mean radial width increased from the initial $0.16 \mathrm{~mm}$ to $0.74 \mathrm{~mm}$ at one year, whereas in the control group it increased from $0.22 \mathrm{~mm}$ to $1.57 \mathrm{~mm}$. The mean ulnar variance decreased from $-1.05 \mathrm{~mm}$ to $-0.25 \mathrm{~mm}$ in the SRS and from $-1.18 \mathrm{~mm}$ to $+1.26 \mathrm{~mm}$ in the control groups, with mean losses at one year of $0.77 \mathrm{~mm}$ and $2.44 \mathrm{~mm}$, respectively. All these differences were statistically significant $(p<0.01)$. By contrast, with the available data the differences in the radial angle and intra-articular gap were not statistically significant. In the SRS group, the mean radial angle decreased from $22.13^{\circ}$ after reduction to $18.62^{\circ}$ at one year, with a mean loss of $3.61^{\circ}$. In the control 


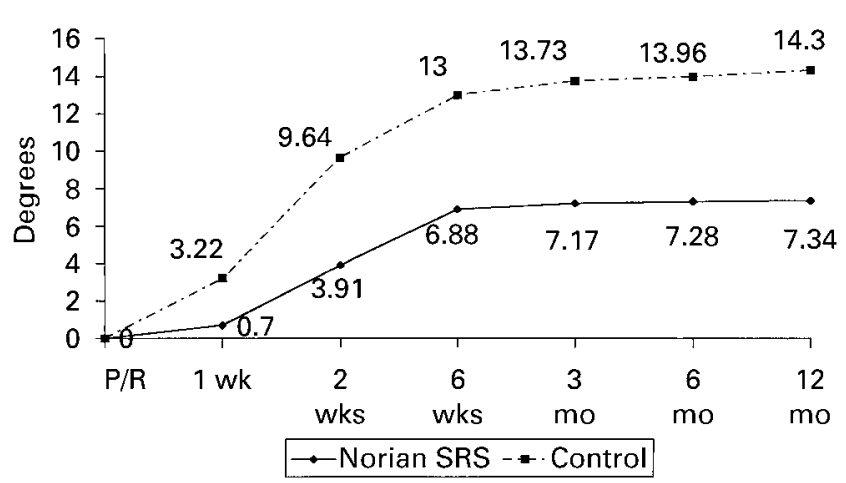

Fig. 2a

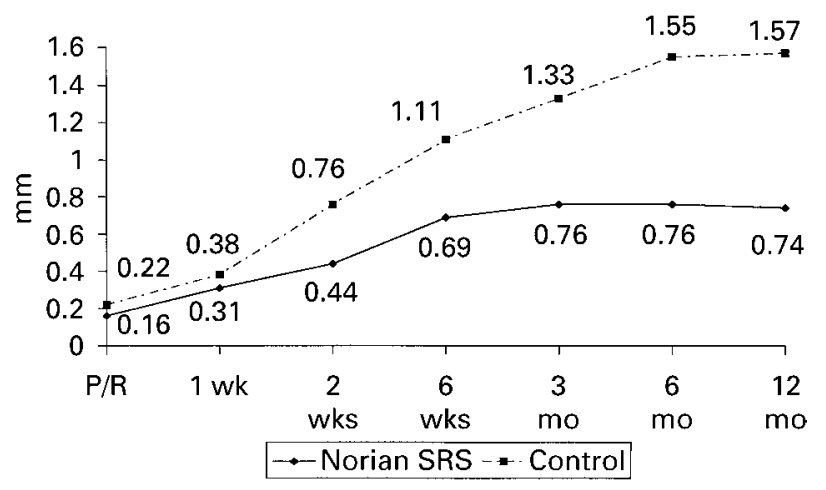

Fig. 2c

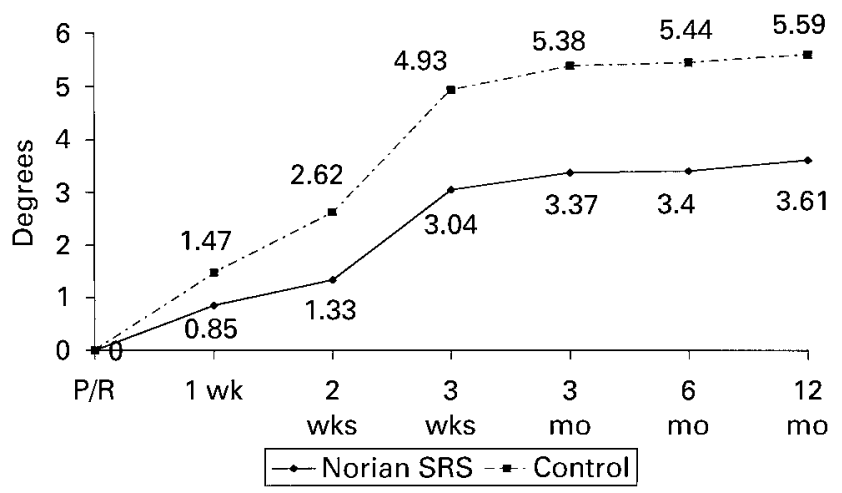

Fig. $2 \mathrm{e}$

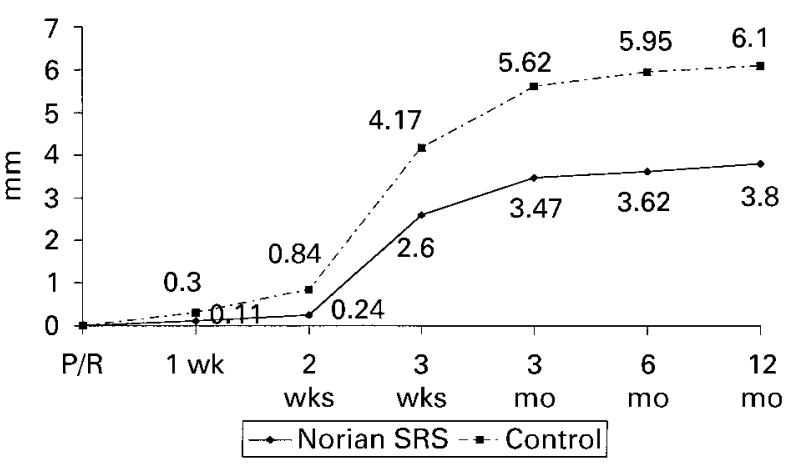

Fig. $2 b$

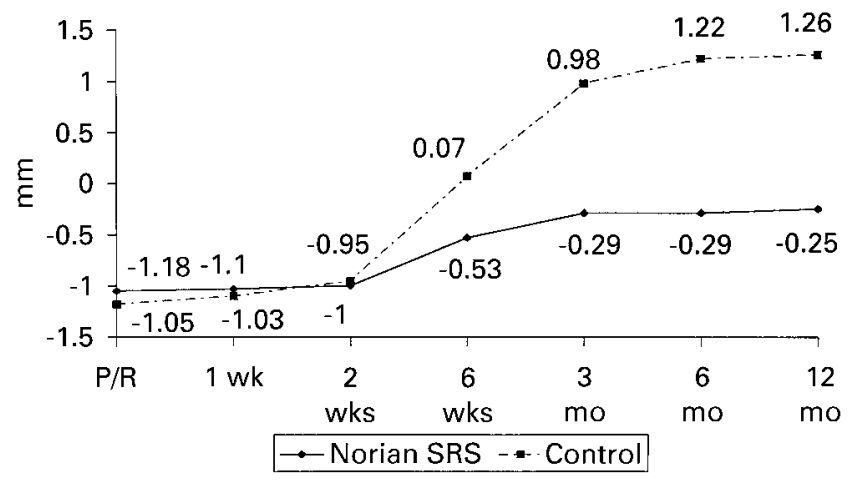

Fig. 2d

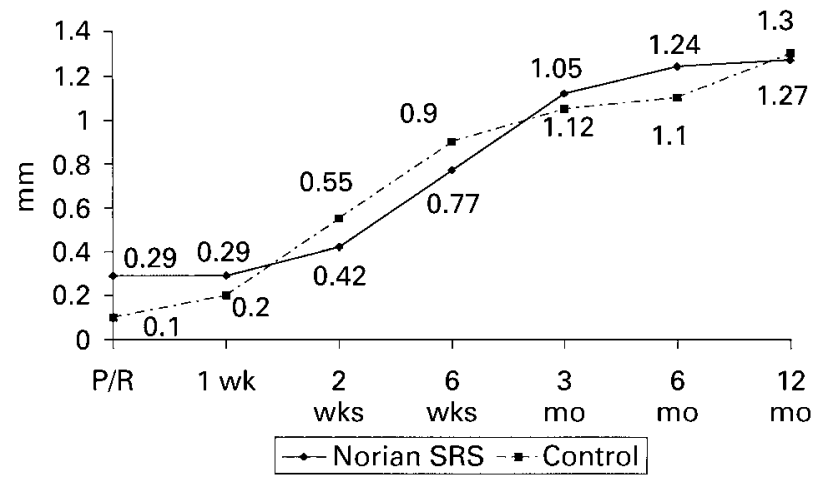

Fig. $2 \mathrm{f}$

Graphs show a) the mean loss of volar angle, b) the mean loss of radial length, c) the mean increase in radial width, d) the mean loss of ulnar variance, e) the mean loss of radial angle, and f) the mean increase in intra-articular gap for up to 12 months for both groups.

group, the mean radial angle measured $22.29^{\circ}$ initially and $16.7^{\circ}$ at one year, with a mean loss of $5.59^{\circ}$. The mean intra-articular gap at the final follow-up was $1.27 \mathrm{~mm}$ in the SRS and 1.3 in the control groups. Malunion, according to the criteria previously defined, was recognised in ten SRS (18.2\%) and 23 control (41.8\%) fractures.

All radiological measurements at one year showed a significant relationship between radiocarpal and radio-ulnar pain and grip strength, both in the whole series and in the SRS and control groups separately. The range of movement in all planes also showed a significant relationship with most of the radiological measurements at final follow-up. The final radiological position seemed to have more influence on flexion and extension than on the other planes of movement. The volar angle and radial length showed the closest correlation with range of movement. The intraarticular gap had no significant relationship to either pronation or radial deviation.

Regression analysis. The three variables with greatest influence on the final functional result were the initial radial length, the type of fracture (A3 or C2) and treatment with or without SRS bone cement, in that order. Once adjusted for other variables, treating a fracture without bone cement multiplied by 12 the probability of having an unsatisfactory result. The four most influential variables on the final radiological result were the initial volar angle, treatment with or without bone cement, age and type of fracture, in that order. After adjustment for other variables, treating a 
Table VI. Complications for each of the two treatment groups, by number and percentage

\begin{tabular}{lcc}
\hline Complication & Norian SRS & Control \\
\hline Malunion & $10(18.2)$ & $23(41.8)$ \\
Compression of the median nerve & $2(3.6)$ & $3(5.4)$ \\
Reflex sympathetic dystrophy & $3(5.4)$ & $4(7.3)$ \\
Rupture of extensor pollicis longus & $2(3.6)$ & $1(1.8)$ \\
Refracture & $1(1.8)$ & 0 \\
Soft-tissue SRS deposits one week after fracture treatment & & - \\
$\quad$ Only volarly & $4(7.3)$ & \\
$\quad$ Only dorsally & $27(49.1)$ & \\
$\quad$ Both & $7(12.7)$ & - \\
$\quad$ Total & $38(69.1)$ & \\
Intra-articular SRS deposits & $1(1.8)$ & \\
\hline
\end{tabular}

fracture without bone cement multiplied by 11 the probability of malunion.

Complications. The specific complications detected in both groups are summarised in Table VI. There were no differences between the rates of compression of the median nerve, reflex sympathetic dystrophy (RSD) or rupture of extensor pollicis longus in the two groups. One patient in the SRS group fell at home and refractured her distal radius three months after the initial injury. The new fracture united in a good position, but the patient still suffers from RSD and her final result is poor. Extrusion of bone cement from within the radius occurred in 38 patients $(69.1 \%$ of SRS cases). Deposits were located in the soft tissues; 27 (49.1\%) patients had deposits in the dorsal soft tissues, four (7.3\%) had deposits in the volar aspect and seven (12.7\%) had

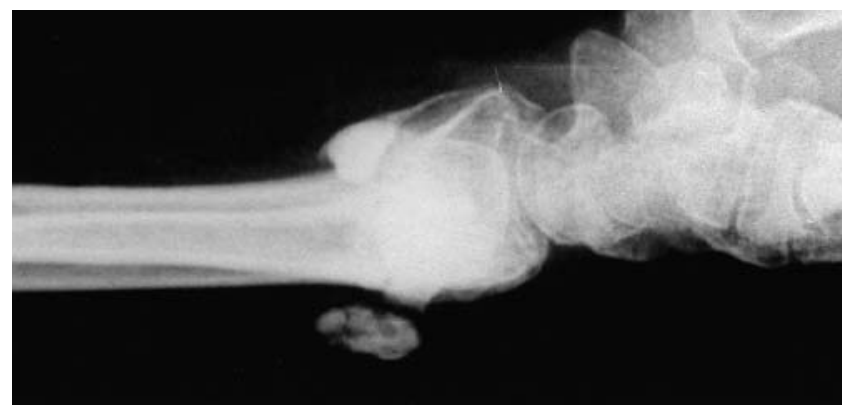

Fig. 3a

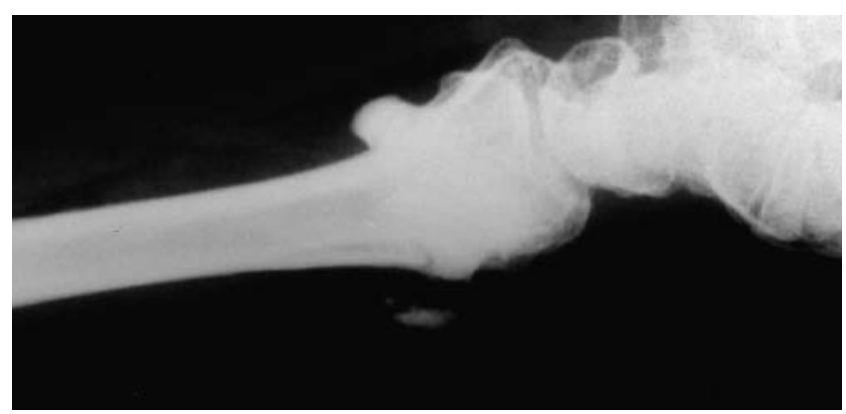

Fig. 3b

Lateral radiographs a) at six weeks and b) at six months showing progressive decrease in volar and dorsal soft-tissue SRS deposits. both. There were fewer extraosseous deposits in the patients treated towards the end of the study, reflecting improving surgical technique. Such extrusion occurred in 24 of the first 27 patients treated (88.9\%) and in 14 of the remaining $28(50 \%)$. This difference is statistically significant $(p<0.01)$. None of the 11 volar deposits gave symptoms; in particular, compression of the median nerve was not found. By contrast, 30 of the 34 patients $(88.2 \%)$ with dorsal soft-tissue extrusion had transient discomfort. Extraosseous deposits progressively decreased during follow-up (Fig. 3), and disappeared completely in 20 of the 38 patients, but persisted in the other $18(32.73 \%)$. One patient in the SRS group had an intra-articular extension of the fracture with extrusion of cement into the radiocarpal joint, requiring surgical removal because of pain. None of the SRS patients showed signs of superficial or deep infection. There was no significant relationship between extraosseous deposits and other complications, including malunion, nerve compression or tendon rupture.

\section{Discussion}

The injection of a remodellable bone cement into the trabecular defect in fractures of the distal radius with cast support for two weeks, provides better clinical and radiological results than conventional treatment in patients over 50 years of age. The range of movement and strength of grip were restored earlier and to a greater extent in patients treated with Norian SRS. Structural reinforcement with this bone cement, however, does not completely eliminate settling of the fracture.

Fracture of the distal radius in the elderly results in a metaphyseal trabecular defect which leads to progressive redisplacement after reduction. ${ }^{1,2}$ Immobilisation in a cast, external fixation and internal fixation with either Kirschner wires or plates are the methods commonly used to try to hold the fracture in a good position until the trabecular defect is filled with new bone. ${ }^{2}$ In many cases, however, reduction is not maintained leading to an unsatisfactory outcome. ${ }^{6}$ Non-bridging external fixation has recently been reported to maintain reduction and restore grip strength and 
range of movement after this fracture. ${ }^{22}$ An alternative approach to deal with the trabecular defect is to fill it primarily with a material which provides immediate structural support, a technique commonly used in other fractures such as those of the tibial plateau. When bone graft or PMMA has been used for structural reinforcement shorter times for immobilisation are achieved with satisfactory functional and anatomical results. ${ }^{6-10}$ Remodellable bone cements such as Norian SRS can be used in a similar way to provide immediate stability and to shorten the length of immobilisation, with the added advantages of availability, biological acceptance and high compressive strength. ${ }^{15-19}$

The choice of conservative treatment for the control group in our study is debatable. Immobilisation in a cast is known to be unsuccessful for unstable fractures of the distal radius, ${ }^{1}$ but other techniques including open bone grafting and bridging external fixation give similar functional results. ${ }^{6}$ Conservative treatment allows a comparison in which only two variables changed between the groups under study, namely treatment with or without SRS and the length of immobilisation. The results of conservative treatment in our control group are similar to those published by other authors ${ }^{1,3,4}$ who consider it to be unsatisfactory for unstable fractures.

In our study, wrist and hand function was restored earlier in the SRS group, probably as a result of the shorter period of immobilisation. Other authors have reported the same functional benefits from structural reinforcement and early movement when compared with treatment imposing more prolonged immobilisation. PMMA with immobilisation in a cast for two weeks provided earlier functional recovery than both conservative treatment ${ }^{9}$ and bridging external fixation. ${ }^{10}$ Function was also restored more quickly with SRS and immobilisation in a cast for two weeks than with external fixation for five weeks. ${ }^{19}$ Non-bridging external fixation also allows early wrist movement and consequently achieves earlier functional restoration, but when structural reinforcement has not been combined with shorter immobilisation, no functional difference has been seen compared with conservative treatment or external fixation. ${ }^{6}$

Whereas a short period of immobilisation is essential for early functional recovery, the long-term results seem to be determined by the restoration of the anatomy ${ }^{2-4}$ and by the rates of complication. ${ }^{23}$ In one study, PMMA and immobilisation in a cast provided a better radiological outcome than conservative treatment; the final functional results were also superior with PMMA. ${ }^{9}$ Our findings with SRS are similar: we observed a better radiological outcome than with conservative treatment and better final function. The rate of malunion, however, in our SRS group was 18.2\%; the combination of SRS with immobilisation in a cast cannot be considered to be a reliable method of preventing malunion in distal radial fractures. When structural reinforcement, including autograft, ${ }^{6}$ PMMA $^{10}$ or Norian $\mathrm{SRS},{ }^{19}$ has been compared with bridging external fixation, no differences have been found in the initial radiological or functional results. When, however, the time of immobilisation has been shortened without the addition of structural reinforcement, the radiological and final functional results have not been as satisfactory. This has been shown with both functional treatment ${ }^{24}$ and dynamic external fixation. $^{6,25}$

Extraosseous extrusion of bone cement was the main complication of treatment with SRS. Volar soft-tissue deposits were asymptomatic but dorsal extrusions caused transient discomfort. Fortunately, as experience is gained, accidental extraosseous deposits occur less frequently. Furthermore, soft-tissue deposits tend to disappear spontaneously $^{17,18}$ (Fig. 3). An intra-articular deposit of SRS occurred in one patient; it was symptomatic and required surgical removal. This complication has not previously been reported and every effort should be made to avoid it, by anatomical reduction of the intra-articular fracture lines, stabilisation with Kirschner wires, and careful injection, initially sealing the intra-articular lines with a bolus of SRS cement. Other complications do not seem to be influenced by the use of SRS. ${ }^{19}$ Infection did not occur in any of our patients and has not been reported by other authors. This compares favourably with external fixation in which pintrack infection commonly occurs. 5,10

The incidence of major complications related to harvesting of autogenous bone graft, such as vascular or nerve lesions, abdominal hernias, pelvic fractures or hip subluxation has varied from $3.4 \%$ to $8.6 \%$ and additional minor complications, such as prolonged serous drainage, haematoma, infection, pain or gluteal anaesthesia occur in $6 \%$ to $10 \% .^{11,12}$ PMMA can cause thermal or toxic local lesions and occasionally impedes union of the fracture; late loosening can occur. ${ }^{14,16} \mathrm{SRS}$ is readily available and biocompatible. Studies in vivo have shown that it is remodelled into natural bone, ${ }^{15}$ although this seems to occur slowly in the distal radius in man.

Our results have shown that, compared with conservative treatment, the use of Norian SRS requires immobilisation of the wrist for only two weeks after fracture of the distal radius and decreases the rate of redisplacement of the fracture. This in turn provides earlier functional recovery and a better final result. The rate of malunion, however, after this method of treatment may call for additional support or fixation in selected cases.

We would like to acknowledge Dr A. Ladd for her revision of the manuscript.

No benefits in any form have been received or will be received from a commercial party related directly or indirectly to the subject of this article.

\section{References}

1. McQueen MM, MacLaren A, Chalmers J. The value of remanipulating Colles' fractures. J Bone Joint Surg [Br] 1986;68-B:232-3.

2. Fernandez DL, Jupiter JB. Fractures of the distal radius: a practical approach to management. New York: Springer-Verlag, 1996.

3. Stewart HD, Innes AR, Burke FD. Factors affecting the outcome of Colles' fracture: an anatomical and functional study. Injury 1985;16:289-95. 
4. McQueen M, Caspers J. Colles' fracture: does the anatomical result affect the final function? J Bone Joint Surg [Br] 1988;70-B:649-51.

5. Cooney WP III, Dobyns JH, Linscheid RL. Complications of Colles' fractures. J Bone Joint Surg [Am] 1980;62-A:613-9.

6. McQueen MM, Hajducka C, Court-Brown CM. Redisplaced unstable fractures of the distal radius: a prospective randomised comparison of four methods of treatment. J Bone Joint Surg [Br] 1996;78-B:404-9.

7. McBirnie J, Court-Brown CM, McQueen MM. Early open reduction and bone grafting for unstable fractures of the distal radius. $J$ Bone Joint Surg [Br] 1995;77-B:571-5.

8. Leung KS, Shen WY, Leung PC, et al. Ligamentotaxis and bone grafting for comminuted fractures of the distal radius. J Bone Joint Surg [Br] 1989;71-B:838-842.

9. Schmalholz A. Bone cement for redislocated Colles' fracture: a prospective comparison with closed treatment. Acta Orthop Scand 1989;60:212-7.

10. Schmalholz A. External skeletal fixation versus cement fixation in the treatment of redislocated Colles' fracture. Clin Orthop 1990;254:236-41.

11. Younger EM, Chapman MW. Morbidity of bone graft donor sites. $J$ Orthop Trauma 1989;3:192-5.

12. Arrington ED, Smith WJ, Chambers HG, Bucknell AL, Davino NA. Complications of iliac crest bone graft harvesting. Clin Orthop 1997;329:300-9.

13. Charnley J. Acrylic cement in orthopaedic surgery. Edinburgh, etc: E \& S Livingstone, 1970.

14. Constantz BR, Ison IC, Fulmer MT, et al. Skeletal repair by in situ formation of the mineral phase of bone. Science 1995;267:1796-9.

15. Frankenburg EP, Goldstein SA, Bauer TW, Harris SA, Poser RD. Biomechanical and histological evaluation of a calcium phosphate cement. J Bone Joint Surg [Am] 1998;80-A:1112-24.
16. Yetkinler DN, Ladd AL, Poser RD, Constantz BR, Carter D. Biomechanical evaluation of fixation of intra-articular fractures of the distal radius in cadavera: Kirschner wires compared with calciumphosphate bone cement. J Bone Joint Surg [Am] 1999;81-A:391-9.

17. Jupiter JB, Winters S, Sigman S, et al. Repair of five distal radius fractures with an investigational cancellous bone cement: a preliminary report. J Orthop Trauma 1997;11:110-6.

18. Kopylov P, Jonsson K, Thorngren KG, Aspenberg P. Injectable calcium phosphate in the treatment of distal radial fractures. $J$ Hand Surg [Br] 1996;21:768-71.

19. Kopylov P, Runnqvist K, Jonsson K, Aspenberg P. Norian SRS versus external fixation in redisplaced distal radial fractures: a randomised study in 40 patients. Acta Orthop Scand 1999;70:1-5.

20. LaFontaine M, Hardy D, Delince PH. Stability assessment of distal radius fractures. Injury 1989;20:208-10.

21. Bradway JK, Amadio PC, Cooney WP. Open reduction and internal fixation of displaced, comminuted intra-articular fractures of the distal end of the radius. J Bone Joint Surg [Am] 1989;71-A:839-47.

22. McQueen MM. Redisplaced unstable fractures of the distal radius: a randomised, prospective study of bridging versus non-bridging external fixation. J Bone Joint Surg [Br] 1998;80-B:665-9.

23. McQueen MM, Michie M, Court-Brown CM. Hand and wrist function after external fixation of unstable distal radial fractures. Clin Orthop 1992;285:200-4.

24. Sarmiento A, Pratt GW, Berry NC, Sinclair WF. Colles' fractures: functional bracing in supination. $J$ Bone Joint Surg [Am] 1975;57-A:311-7.

25. Sommerkamp TG, Seeman M, Silliman J, et al. Dynamic external fixation of unstable fractures of the distal part of the radius: a prospective, randomised comparison with static external fixation. $J$ Bone Joint Surg [Am] 1994;76-A:1149-61. 